\title{
Excess Capacity of Higher Education Products Based on Duopoly Model*
}

\author{
Bin $\operatorname{Liu}^{1}$ \\ Changchun Normal University \\ Xiaomeng Wang ${ }^{3}$ \\ Northeastern University at \\ Qinhuangdao
}

\author{
Yajie Wang ${ }^{2}$ \\ Northeastern University at Qinhuangdao \\ Junlong Chen ${ }^{4}$ \\ Northeastern University, Northeastern \\ University at Qinhuangdao
}

\begin{abstract}
China's higher education is facing a structural excess capacity crisis. Duopoly models that consist of two universities are constructed in attempt to investigate the impacts of demand price elasticity, product differentiation, subsidies, and cost efficiency on excess capacity. In doing so, it turns out that the ownership of capacity decision power in higher education will exert an effect on the extent of excess capacity and the impact on the product differentiation on excess capacity. The higher the subsidies granted to universities or the lower the cost, the more the excess capacity in one university, but the less in the other university. When universities have the capacity decision power, the demand price elasticity and excess capacity constitute a Type U relationship. While the government owns the capacity decision power, both are positively correlated to each other. These conclusions have a certain realistic significance for the higher education reform in China.
\end{abstract}

\section{Keywords}

Double oligopoly $\bullet$ University $\bullet$ Excess Capacity

\footnotetext{
* The work was supported by "the Fundamental Research Funds for the Central Universities" (NO. N172304021) and "the Natural Science Foundation of Hebei Province of China" (NO. G2018501047).

${ }^{1}$ Office of International Cooperation and Exchanges, Changchun Normal University, Changchun 130032, China. Email: ccsyliubin@126.com

${ }^{2}$ School of Economics, Northeastern University at Qinhuangdao, Qinhuangdao 066004, China. Email: Olivia9264@163.com

${ }^{3}$ School of Economics, Northeastern University at Qinhuangdao, Qinhuangdao 066004, China. Email: m15076207569@163.com

${ }^{4}$ Correspondence to: School of Business Administration, Northeastern University, Shenyang 110819, China; School of Economics, Northeastern University at Qinhuangdao, Qinhuangdao 066004, China. Email: shikuangzhiwang@126.com.
} 
Education, as a public product in the traditional sense, has long been the focus of public expenditures of governments all over the world. The government's fiscal burden will hike up if all educational products are offered and produced by the government. Moreover, some educational products are exclusive and competitive to some extent. In order to avoid "free rider", many educational fields require the intervention of market mechanisms. As a component of educational products, higher education is commonly seen as a quasi-public good with certain exclusivity and is generally provided by both government and market. All countries in the world attach great importance to the higher education and have invested huge sums in this industry in attempt to cultivate a large pool of talents required for social and economic development, effectively filling up the gap in the market supply of higher education products. As the world's largest developing country, China racks up the investments in higher education. The funding for higher education in China has increased from RMB 293.888 billion in 2006 to RMB 1011 billion in 2016, which has increased by 2.44 times. As of 2015, the average per capita educational expenditure in public finance budget of the ordinary universities countrywide hit upon RMB 18,144, 3.4 times the figure of RMB 5376 in 2005, and the average annual growth rate was $12 \%$. While the average per capita public spending in public finance of the ordinary universities was RMB 8,280, 3.7 times the figure of RMB 2,238 in 2005, and the annual average growth rate was 14\%. As of 2016, there were 2,596 ordinary universities in China including 1,237 undergraduate institutions which enrolled 4.05 million students in total. The existing students in the universities exceeded 16.13 million, and the number of ordinary undergraduates was greater than 3.74 million. As above, China has become a big country for higher education causes.

But unfortunately, China's higher education has exposed the structural surplus caused by increasingly expanded scale. On the one hand, from the aggregate perspective, there is still much room for the proportion of people receiving higher education to grow. In 2016, in China, the population with junior college degree or above accounted for $12.94 \%$ of those who are over 6 years old, and the gross enrollment rate of higher education was $42.7 \%$. Obviously, the higher education is striding forward from the mass stage of education to the stage of popularization. In 2009, the gross enrollment rate of higher education is $89 \%$ in America, 59\% in the United Kingdom, 55\% in France, and 59\% in Japan. It is obvious that, in relation to developed countries such as the United States, Britain, France, and Japan, the higher education in China still has much room for upswing. On the other hand, as the age-appropriate population decline, coupled with grim employment situation for students, the demand for higher education will significantly contract year by year, and the relationship between supply and demand scales for higher education in the market of students will be turned around. At the end of the last century, however, the capacity built up by the great scale of enrollment in universities has not yet been digested completely. Consequently, there is a serious shortage of enrollment in private universities, so that the competition among higher education institutions for students has become increasingly fierce. Since 1998, the number of students who sign up for examination in China's universities has shot up. This figure hit the peak of 10.5 million in 2008, but swooped after 2009. The number of entries in 2009 was 10.2 million, but went down to 9.46 million in 2010, with a decrease of 104 million people. The entries in the next few years showed a downward trend, that is, 9.4 million in 2017. But the other way around, the universities have proliferated year by year with this trend. There were 2,596 in 2016, doubled the figure of 1041 in 2000. Their enrollment rates have presented a dynamic upward trend since 1977. 
Liu, Wang, Wang, Chen / Excess Capacity of Higher Education Products Based on Duopoly Model

The excess capacity, as a common phenomenon in the market economy, was first proposed by (Chamberlin, 1933). On the basis of the full capacity as defined, he pioneered to systematically explain the concept of "Excess Capacity" from a microeconomic perspective and also stated that the full capacity was the output level under the perfect competition and equilibrium conditions. Otherwise, imperfect competition would lead to the inefficiency of economic organizations and further link to excess capacity. This concept was widely used in the industrial field once proposed. Scholars interpreted it from the business, industry, and macroeconomic levels. With different outlooks, scholars generally believed that excess capacity was a resource waste caused by nonoptimized allocation for these resources in this industry, but its impact on economic efficiency was negative (Liu and Sun, 2014; Hu, 2016). The capacity concept also has certain applicability in the field of education since the higher education has been partially industrialized with the development of society and economy, especially inspired by continuous advancement of information technology. Although China's universities are non-profit organizations, there are still conflicts of interest between each other. How to enroll premium students is the core that universities compete for. As suppliers of the higher education market, they offer special products to the vase amount of test takers with academic education, i.e. knowledge. As the demanders for higher education, age-appropriate people purchase the higher education products by spending time and paying tuition fees. If they supply too many products but the demand is relatively scarce, then the educational capacity will be idle, resulting in excess capacity. (Yuan, 2010) believed that the capacity expansion rate far exceeded the speed of future demand increase despite of rapidly outspreading enrollment scale at the peril of excess capacity. (Zhang, 2012) argued that the excess capacity of the Chinese higher education industry had a dual nature. From the labor market perspective, China's higher education now presents a momentum of "Immediate excess capacity". While in the market of students, the higher education industry has a great possibility of "expected excess capacity".

In what the excess capacity is deeply rooted is the focus that scholars' debate and research as the most controversial issue. They explained it from a variety of perspectives, both theoretically and empirically, to effectively reveal the origin of excess capacity. In a word, the excess capacity is mainly attributed to market organization structure and corporate behavior (Dixit and Stiglitz, 1977), information asymmetry and industrial characteristics, (Xu and Zhou, 2015), government system (Yu and Lv, 2015). On the whole, the scholars' perspectives differ a lot. Whether the excess capacity attributes to the "market failure" or "government failure" is just the other focus scholars' debate. As is specific to the excess capacity in the context of China, except for some scholars represented by (Lin, Wu and Xing, 2010) who believed it was ascribed to market factors such as market depression, "surge phenomenon" and cyclical fluctuations of economy, most argued that excess capacity derived from unreasonable administrative intervention of the government. A majority of scholars have interpreted excess capacity based on different government behaviors, along with continuously deepened analysis on this "government failure" (Zhou and Liao, 2014; He and He, 2016). In fact, to dig up the root of excess capacity, both government and external market factors should be included for overall consideration. Enlightened by this, this paper reveals the structural excess capacity in China's higher education from multiple perspectives. 


\section{Methodologies}

So how can we explain the excess capacity in the education industry? This paper intends to use the duopoly model method to survey the mutual game between two players in a specific market, thus draw the optimal decision under Subgame Perfect Nash Equilibrium (SPNE). The duopoly model method is an effective method to investigate the rational decision behavior of market players. On the one hand, the single investigation on the competition between the two market players will help simplify the analysis and make it easier to draw conclusions. Intrinsic mechanism that it reveals is equally applicable to competition among multiple players, and easier to deepen expansion. On the other hand, it can be applied to the macroeconomic area with welldesigned elements such as competition type, cost and utility function, etc. Just as above, the duopoly model is an effective method widely used in the economics circles. It has also been proven through practices that conclusions drawn have strong explanatory power and applicability.

Some scholars have used duopoly model to explore the excess capacity. Multi-stage game analysis of capacity and output has revealed the formation mechanism of excess capacity under the state of oligopoly competition equilibrium. Both excess capacity and crunch capacity might become the outcomes derived from this state. Survey results show that excess capacity is ubiquitous in a plurality of private oligopolistic markets. (Ogawa, 2006; Bárcena-Ruiz and Garzón, 2007) respectively explored the option of production capacities under product heterogeneity in the mixed oligopoly market where there were both yield and price competitions. Scholars have some controversies about whether state-owned property rights will inevitably lead to excess capacity. It's an important argument in the academic circle. (Wen and Sasaki, 2001) believed that under the duopoly competition equilibrium state, excess capacity in businesses would occur. Under the SPNE, excess capacity exists in state-owned enterprises. However, (Tomaru, Nakamura and Saito, 2011; Nakamura, 2014) worked out contradicted conclusions that it was not bound for excess capacity to appear in the state-owned enterprises using different types of mixed oligopoly models. These conclusions can be used for references in the discussion on whether excess capacity emerges in the higher education as a quasi-public product. Education may not only result in crunch capacity, but also impose excess capacity under ad hoc conditions. In the course of the study, some scholars including (Nishimori and Ogawa, 2004) adopted simultaneous game analysis. Others resorted to the sequential game. Lu and Poddar (2005a) used a sequential game analysis. Their results reveal that state-owned enterprises have never chosen excess capacity, while private companies have never preferred crunch capacity. Subsequently, Lu and Poddar (2006b) studied the option of business capacities under uncertainty condition. In reality, market players often prefer the capacity rather than the yield for production. This paper therefore intends to adopt the sequential game method.

The existing studies are regarded as a powerful reference for building a duopoly model that complies with the higher education practices in China. This paper attempts to design a duopoly model composed of universities among which the competition behaviors in the market of students are exposed with sequential games at multiple stages. The structural excess capacity in higher education in China is further revealed as a phenomenon. It strikes an appropriate idea for higher education reform. Compared to the previous findings, the new idea of this paper is that: when constructing the duopoly model composed of universities, we fully allow for the 
characteristics of quasi-public product and practical situation in China's higher education market to make it have more realistic explanatory power. The studies on the excess capacity are expanded from the simple business to the education fields, focusing more on the higher education product supply. The paper reveals the origin of the excess capacity of higher education products from both the internal and external levels, and makes up for the defects from a single perspective.

\section{Model construction}

As required in the study, to construct a duopoly model composed of two universities in the student source market, there are some specific assumptions to be made as follows:

Hypothesis 1: Assume that there are two universities called university 1 and university 2, which produce the higher education products, and compete for the students in the market with their respective products. They carry out the Cournot competition mode with the number of higher education products. There are two types of incomes. One is the consumption that students make in the campus and universities benefit from, such as student tuition, the higher the income, the more students are cultured. On the other hand, they profit from government subsidies due to the public nature of higher education. It's the distinctive between higher education products and private products. In the case of high subsidies, the students will be charged for lower tuition. For example, the tuitions for higher education in China have been strictly controlled by the state at a much lower growth rate, and even generally lower than preschool education.

Hypothesis 2: Assume that the functions of market demand that two universities face are: $p_{i}=a-$ $\eta\left(q_{i}+r q_{j}\right), i, j=1,2$, and $i \neq j$ a is a constant greater than zero; $r$ indicates the degree of product homogeneity, and $0 \leq \mathrm{r} \leq 1$; the greater the value, the more homogenous the product is, otherwise the greater the difference is; $\eta$ represents the sensitivity of demand for student source market to the price, $\eta>0$, the higher the value, the more sensitive the demand of the student source market is to the price, which means that the lower the price elasticity of demand for higher education products, the less sensitive it is to price. These are external factors that affect excess capacity. Potential students in the source market choose whether to accept higher education based on the level of individual payments.

Hypothesis 3: Capacity refers to the scale of students supported with the university's hardware and software facilities and teachers, which is equivalent to the scale of enrollment. Yield refers to the actual number of students actually enrolled in the competition market. Capacity decision is divided into two types, one is determined at the discretion of universities, and the other is determined by the government in accordance with social welfare maximum criteria.

Excess capacity will be extravagant in educational resources, resulting in additional cost loss. Crunch capacity will lead to overcrowding problems, impact the quality of teaching and the source of students. In order to reflect the additional costs incurred by unbalanced capacity for universities, the paper refers to the models of Vives (1986), Tomaru et al. (2011). Assume that the capacities and yields of the two universities are $x_{i}, q_{i}, i=1$ or 2 , respectively. The overall social welfare $W=p s+c s$, where, $c s$ represents the consumer surplus cs $=$ 
Liu, Wang, Wang, Chen / Excess Capacity of Higher Education Products Based on Duopoly Model

$\overline{\frac{\eta\left(q_{1}^{2}+q_{2}^{2}+2 r q_{1} q_{2}\right)}{2} ; p s \text { represents the producer surplus } p s=\pi_{1}+\pi_{2} \text {, where } \pi_{i}=p_{i} q_{i}+b_{i} q_{i}-\left[c_{i} q_{i}+\left(x_{i}-\right.\right.}$ $\left.\left.q_{i}\right)^{2}\right] ; b_{i}$ is the subsidy government grants for each student in the universities; $c_{i}$ is the marginal cost of each university, these two variables, plus the product differentiation, are internal factors affecting the university's excess capacity.

Under the above preconditions, the two parties perform a sequential game in the two stages, including:

Stage 1, the two universities determine the scale of enrollment based on the principle of maximizing profits or social welfare, i.e. $x_{1}, x_{2}$.

Stage 2, the two universities carry out Cournot competition around production output and determine the optimal number of enrollments, namely, $q_{1}, q_{2}$.

\section{Model analysis}

In order to solve the two-stage equilibrium solution, we make analysis according to backward induction. First, survey the stage 2 game. Based on the profit maximization principle, the decision about the number of actual enrollment students in two universities need to meet:

$\frac{\partial \pi_{1}}{\partial q_{1}}=(-2 \eta-2) q_{1}-\eta r q_{2}+a+b_{1}-c_{1}+2 x_{1}=0$ and $\frac{\partial \pi_{2}}{\partial q_{2}}=(-2 \eta-2) q_{2}-\eta r q_{1}+a+b_{2}-c_{2}+$ $2 x_{2}=0$. The equilibrium output can be deduced:

$$
\begin{aligned}
& q_{1}=\frac{\eta\left[r\left(a+b_{2}-c_{2}+2 x_{2}\right)-2 a-2 b_{1}+2 c_{1}-4 x_{1}\right]-2 a-2 b_{1}+2 c_{1}-4 x_{1}}{-4+\left(r^{2}-4\right) \eta^{2}-8 \eta} \\
& q_{2}=\frac{\eta\left[r\left(a+b_{2}-c_{1}+2 x_{1}\right)-2 a-2 b_{2}+2 c_{2}-4 x_{2}\right]-2 a-2 b_{2}+2 c_{2}-4 x_{2}}{-4+\left(r^{2}-4\right) \eta^{2}-8 \eta}
\end{aligned}
$$

Second, survey the stage 1 game in two cases:

\section{Pursuit of maximum profit}

Based on the principle of profit maximization, the decisions on the enrollment scales of the two universities needs to meet: $\frac{\partial \pi_{1}}{\partial x_{1}}=0$ and $\frac{\partial \pi_{2}}{\partial x_{2}}=0$, substitute formulas (1) and (2) into the profit function, a balanced enrollment scale for both parties can be deduced and a balanced capacity will be available, as shown below:

$$
\begin{aligned}
& -\left(\left(4\left(\left(a+b_{2}-c_{2}\right) r-2 a-2 b_{1}+2 c_{1}\right)(r+2)(r-2) \eta^{2}+4\left(\left(-2 a-2 b_{1}+2 c_{1}\right) r^{2}\right.\right.\right. \\
x_{1}= & \frac{\left.\left.\left.+\left(-8 a-8 b_{2}+8 c_{2}\right) r+16 a+16 b_{1}-16 c_{1}\right) \eta+4\left(-4 a-4 b_{2}+4 c_{2}\right) r+32 a+32 b_{1}-32 c_{1}\right)(\eta+1)^{2}\right)}{\left(\left((r+2)^{2}(r-2) \eta^{2}+\left(2 r^{2}-8 r-16\right) \eta-4 r-8\right)\left((r+2)(r-2)^{2} \eta^{2}+\left(-2 r^{2}-8 r+16\right) \eta-4 r+8\right) \eta\right)} \\
& -\left(4 ( \eta + 1 ) ^ { 2 } \left(\left(\left(a+b_{1}-c_{1}\right) r-2 a-2 b+2 c_{2}\right)(r+2)(r-2) \eta^{2}+\left(\left(-2 a-2 b_{2}+2 c_{2}\right) r^{2}+\left(-8 a-8 b_{1}+8\right.\right.\right.\right. \\
x_{2}= & \frac{\left.\left.\left.\left.c_{1}\right) r+16 a+16 b_{2}-16 c_{2}\right) \eta+\left(-4 a-4 b_{1}+4 c_{1}\right) r+8 a+8 b_{2}-8 c_{2}\right)\right)}{\left(\left((r+2)^{2}(r-2) \eta^{2}+\left(2 r^{2}-8 r-16\right) \eta-4 r-8\right)\left((r+2)(r-2)^{2} \eta^{2}+\left(-2 r^{2}-8 r+16\right) \eta-4 r+8\right) \eta\right)} \\
& \left(( 2 + ( r + 2 ) \eta ) \left(\left(\left(a+b_{2}-c_{2}\right) r-2 a-2 b_{1}+2 c_{1}\right)(r+2)(r-2) \eta^{2}+\left(\left(-2 c-2 b_{1}+2 c_{1}\right) r^{2}+\left(-8 a-8 b_{2}\right.\right.\right.\right. \\
q_{1}= & \frac{\left.\left.\left.\left.+8 c_{2}\right) r+16 a+16 b_{1}-16 c_{1}\right) \eta+\left(-4 a-4 b_{2}+4 c_{2}\right) r+8 a+8 b_{1}-8 c_{1}\right)(-2+(r-2) \eta)\right)}{\left(\left((r+2)^{2}(r-2) \eta^{2}+\left(2 r^{2}-8 r-16\right) \eta-4 r-8\right)\left((r+2)(r-2)^{2} \eta^{2}+\left(-2 r^{2}-8 r+16\right) \eta\right)\right.}
\end{aligned}
$$


Liu, Wang, Wang, Chen / Excess Capacity of Higher Education Products Based on Duopoly Model

$\left((2+(r+2) \eta)\left(\left(\left(a+b_{1}-c_{1}\right) r-2 a-2 b_{2}+2 c_{2}\right)(r+2)(r-2) \eta^{2}+\left(\left(-2 c-2 b_{2}+2 c_{2}\right) r^{2}+\left(-8 a-8 b_{1}\right.\right.\right.\right.$ $q_{2}=\frac{\left.\left.\left.\left.+8 c_{1}\right) r+16 a+16 b_{2}-16 c_{2}\right) \eta+\left(-4 a-4 b_{1}+4 c_{1}\right) r+8 a+8 b_{2}-8 c_{2}\right)(-2+(r-2) \eta)\right)}{\left(\left((r+2)^{2}(r-2) \eta^{2}+\left(2 r^{2}-8 r-16\right) \eta-4 r-8\right)\left((r+2)(r-2)^{2} \eta^{2}+\left(-2 r^{2}-8 r+16\right) \eta\right)\right.}$

Subtract output from capacity; we can get the degree of excess capacity:

$$
\begin{gathered}
-\left(\left(\left(\left(a+b_{2}-c_{2}\right) r-2 a-2 b_{1}+2 c_{1}\right)(r+2)(r-2) \eta^{2}+\left(\left(-2 a-2 b_{1}+2 c_{1}\right) r^{2}\right.\right.\right. \\
x_{1}-q_{1}=\frac{\left.\left.\left.+\left(-8 a-8 b_{2}+8 c_{2}\right) r+16 a+16 b_{1}-16 c_{1}\right) \eta+\left(-4 a-4 b_{2}+4 c_{2}\right) r+8 a+8 b_{1}-8 c_{1}\right) r^{2} \eta\right)}{\left(\left((r+2)^{2}(r-2) \eta^{2}+\left(2 r^{2}-8 r-16\right) \eta-4 r-8\right)\left((r+2)(r-2)^{2} \eta^{2}+\left(-2 r^{2}-8 r+16\right) \eta-4 r+8\right)\right)} \\
x_{2}-q_{2}=\frac{\left.\left.\left.+\left(-8 a-8 b_{1}+8 c_{1}\right) r+16 a+16 b_{2}-16 c_{2}\right) \eta+\left(-4 a-4 b_{1}+4 c_{1}\right) r+8 a+8 b_{2}-8 c_{2}\right) \eta\right)}{\left(\left((r+2)^{2}(r-2) \eta^{2}+\left(2 r^{2}-8 r-16\right) \eta-4 r-8\right)\left((r+2)(r-2)^{2} \eta^{2}+\left(-2 r^{2}-8 r+16\right) \eta-4 r+8\right)\right)}
\end{gathered}
$$

Survey the impact of $r$, subsidy and cost differentiations on excess capacity under different demand price elasticity. First, the impact of $r$ on excess capacity was investigated. Using MAPLE2017 to simulate it, it is found that under different demand price elasticity, the lower product differentiation is subjected to the worsening of excess capacity in both universities. For example, if a $=10, b_{1}=b_{2}=1, c_{1}=c_{2}=1$, see Fig. 1.

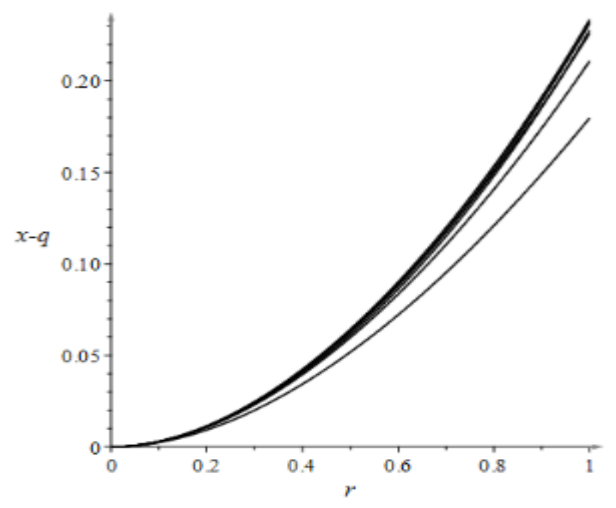

Figure 1. Impact of $\mathrm{r}$ in the case that universities master the capacity decisions

Note: From top to bottom, $\eta$ is $1.2,1.0,1.4,1.6,0.8,0.6,0.4$, respectively.

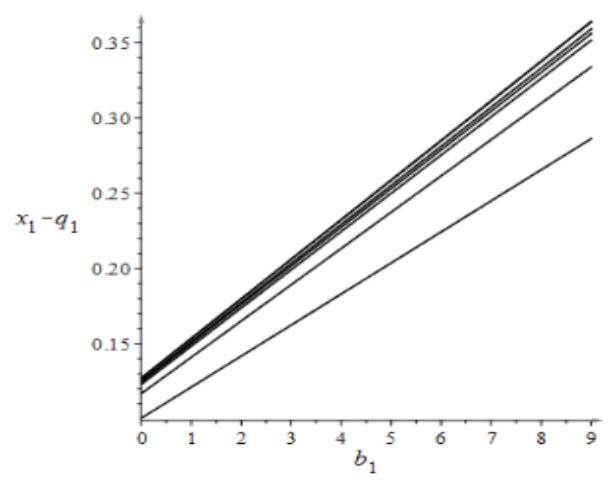

Figure 2. Impact of $b_{1}-b_{2}$ on the university 1 excess capacity when universities master capacity decisions

Note: From top to bottom, $\eta$ is $1,1.2,1.4,0.8,1.6,0.6,0.4$, respectively, Id. Figs. 3-6. 
Second, analyze the impact of the difference $b_{1}-b_{2}$ in subsidies between the two universities on the degree of excess capacity. It is found that if the output, capacity, price, and profit are not negative simultaneously, as the value of $b_{1}-b_{2}$ increase, so does the $x_{1}-q_{1}$, and the degree of excess capacity goes up; as $x_{2}-q_{2}$ decreases, the degree of excess capacity will decline; for example, assume $a=10, b_{2}=1, c_{1}=c_{2}=1, r=0.8$, see Figs. 2 and 3.

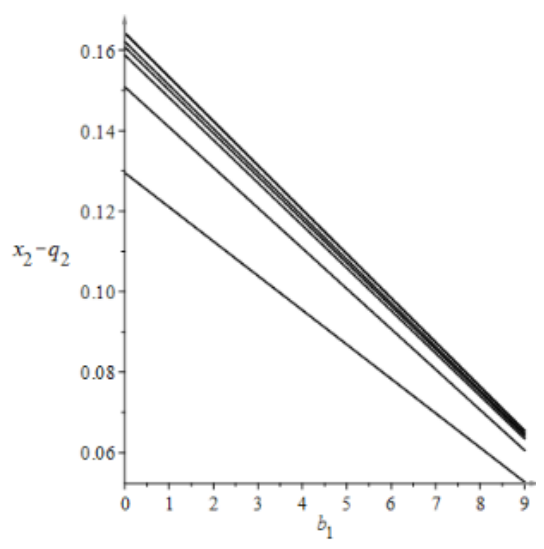

Figure 3. Impact of $b_{1}-b_{2}$ on the university 2 excess capacity when universities master capacity decisions

Third, the impact of cost difference $c_{1}-c_{2}$ on the degree of excess capacity is measured. It is found by simulation that as $c_{1}-c_{2}$ increases, $x_{1}-q_{1}$ will decrease and $x_{2}-q_{2}$ will increase. That is, the impact on the excess capacity of the two universities is the opposite. For example, assume $a=10, b_{1}=b_{2}=1, c_{1}=1, r=0.8$, see Figs. 4 and 5.

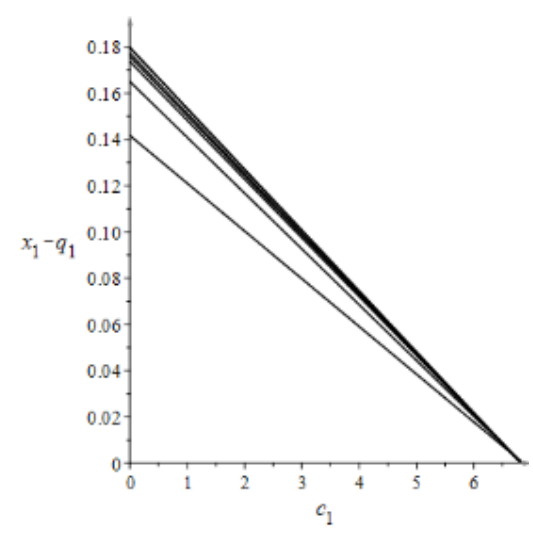

Figure 4. Impact of $c_{1}-c_{2}$ on the university 1 excess capacity when universities master capacity decisions 


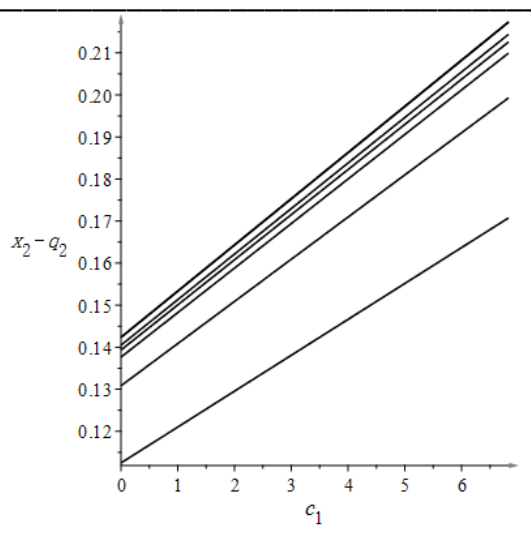

Figure 5. Impact of $c_{1}-c_{2}$ on the university 2 excess capacity when universities master capacity decisions

Proposition 1: Under the condition that the capacity decision is owned by universities, the more homogenous the educational products of the two universities, the worse the excess capacity. The higher the subsidies of a university, the worse its excess capacity, while the lower the degree of excess capacity of the other university. If the cost of a university increases, the degree of excess capacity will decline, and the condition of excess capacity will be much worse. The above simulation can measure the impact of $\eta$ on excess capacity, Proposition 2 can be obtained.

Proposition 2: in the case that universities master capacity decisions, there is a specific level of demand price elasticity as the functions of product, subsidy, and cost. To be below or above this level will result in alleviation of excess capacity since the demand price elasticity affects both capacity and output, but there is a difference in the impact intensity. When a specific level is reached, the capacity and output reach the highest values.

It may be discovered that excess capacity will arise when universities have independent decision power. This is the result that universities blindly pursue the profit maximization. In order to generate higher revenues, they are trapped in the "Prisoner's Dilemma" for competing their respective capacity expansion. In this sense, if universities have the advantage of information and actually have controlled the capacity decision power of higher education, they have motives to expand their capacities, in turn resulting in excess capacity. Since 1999, Chinese universities have continuously expanded their enrollment scales, but due to the more relaxed regulations, some universities have the power to make the capacity decisions, resulting in an over-hasty and too fast phenomenon, thus forming excess capacity to a certain extent.

\section{Government controls the capacity decision power}

Now the assumption is turned into such that if the capacity decision power is controlled by the government, the capacity game in the second stage needs to satisfy the social welfare maximization, i.e. $\frac{\partial \mathrm{W}}{\partial x_{1}}=0$ and $\frac{\partial \mathrm{W}}{\partial x_{2}}=$ 0 . The balanced enrollment scales in the two univerities are: 
Liu, Wang, Wang, Chen / Excess Capacity of Higher Education Products Based on Duopoly Model

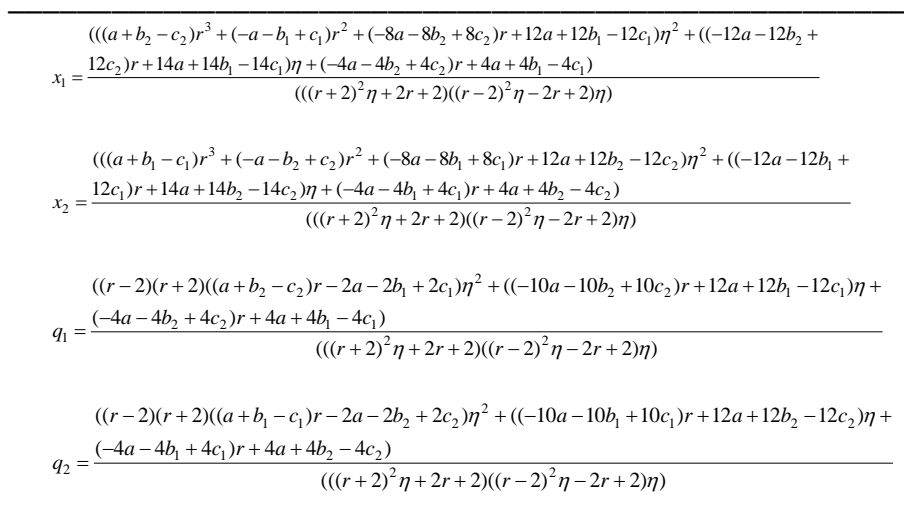

Subtract the output from the capacity; we obtain the degree of excess capacity:

$$
\begin{aligned}
& x_{1}-q_{1}=\frac{\left(\left(\left(a+b_{1}-c_{1}\right) r^{2}+\left(-4 a-4 b_{2}+4 c_{2}\right) r+4 a+4 b_{1}-4 c_{1}\right) \eta+\left(-2 a-2 b_{2}+2 c_{2}\right) r+2 a+2 b_{1}-2 c_{1}\right)}{\left((r+2)^{2} \eta+2 r+2\right)\left((r-2)^{2} \eta-2 r+2\right)} \\
& x_{2}-q_{2}=\frac{\left(\left(\left(a+b_{2}-c_{2}\right) r^{2}+\left(-4 a-4 b_{1}+4 c_{1}\right) r+4 a+4 b_{2}-4 c_{2}\right) \eta+\left(\left(2 a-2 b_{1}+2 c_{1}\right) r+2 a+2 b_{2}-2 c_{2}\right)\right.}{\left((r+2)^{2} \eta+2 r+2\right)\left((r-2)^{2} \eta-2 r+2\right)}
\end{aligned}
$$

According to the simulation method used in the case of profit maximization, the impacts of $r$, subsidy and cost differences on excess capacity are measured on the same assumption for value assignment, as shown in Fig. 7-11.

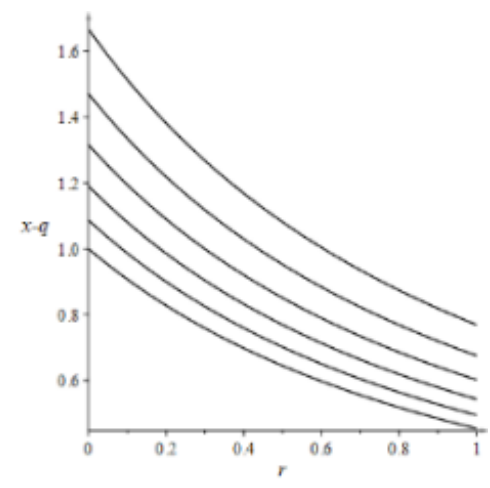

Figure 7. Impact of product differentiation on excess capacity when government owns the capacity decision power

Note: From the top to the bottom, $\eta$ is 1.0, 1.2, 1.4, 1.6, 1.8, and 2.0, respectively. Id. Fig. 8-11.

As shown in Fig. 7, as $r$ increases, $x-q$ will decrease, that is, the degree of excess capacity will decline. Unlike the universities which have the capacity decisions power, on the one hand, the relationship of $r$ with excess capacity reverses in this case. Because the government tends to expand production capacity in order to increase social welfare in the case of product differentiation. Capacity decisions also affect output decisions, resulting in decline of output. 


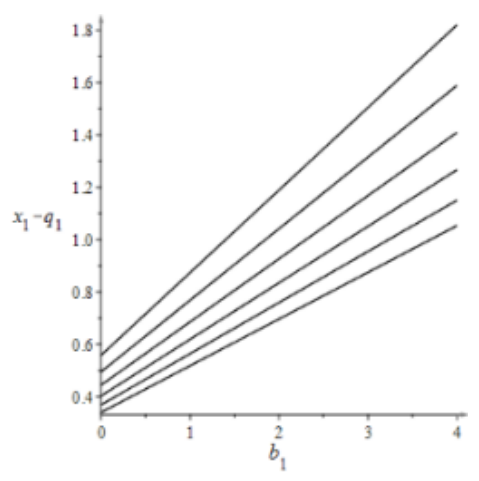

Figure 8. Impact of $b_{1}-b_{2}$ on university 1 excess capacity when government owns the capacity decision power

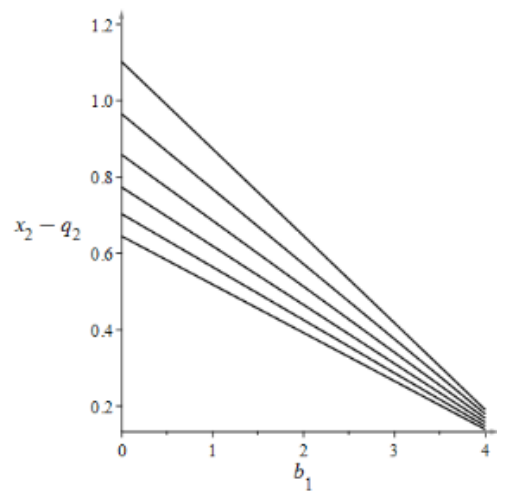

Figure 9. Impact of $b_{1}-b_{2}$ on university 2 excess capacity when government owns the capacity decision power

As shown in Fig. 8 -9, when $b_{1}-b_{2}$ increases, $x_{1}-q_{1}$ will also increase, while $x_{2}-q_{2}$ will decrease. This result coincides with that when the universities own the capacity decision power.

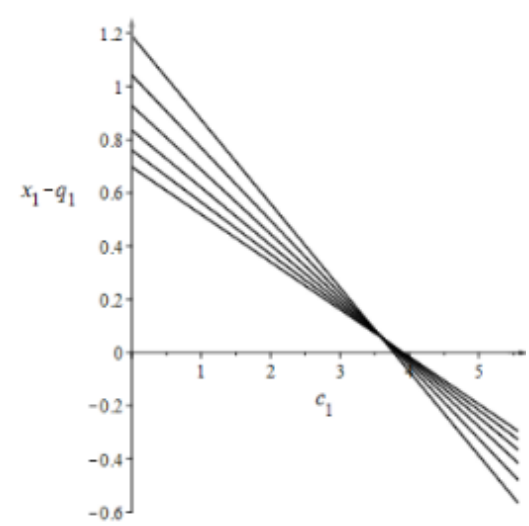

Figure 10. Impact of $c_{1}-c_{2}$ on university 1 excess capacity when government owns the capacity decision power 


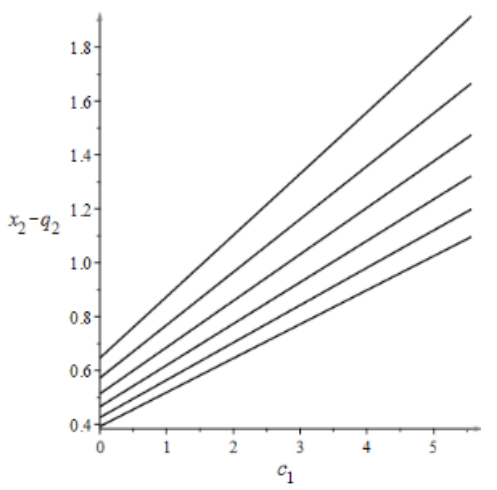

Figure 11. Impact of $c_{1}-c_{2}$ on university 2 excess capacity when government owns the capacity decision power

As shown in Fig. 10 and 11, it is obvious that, as $c_{1}-c_{2}$ increases, $x_{1}-q_{1}$ will decrease, while $x_{2}-q_{2}$ will increase. But when $c_{1}$ is greater than a certain value, for example, 4 , there will still be insufficient capacity. In addition, analyzing the impact of $\eta$ on excess capacity, it is found from Fig. 6-10 that, as $\eta$ increases, $x_{i}-q_{i}$ will decrease and excess capacity will decrease in most cases. Thereby, proposition 3 is deduced.

Proposition 3: In the case that the government controls the production capacity decision, the impact of government subsidy and cost differentiations on the excess capacity level is consistent with the case when the university has owned the capacity decision power. The difference is that there is a positive correlation between product differentiation and excess capacity. When the demand price elasticity falls below a certain level, insufficient capacity will appear. $\eta$ and excess capacity level are negatively related in most cases.

It is found from the comparison that, compared with the case when universities have capacity decision authority, under the regulation of government's capacity based on the maximum of social welfare, excess capacity will still appear, even worse than ever, but insufficient capacity will also emerge under specific conditions, resulting in inefficiency allocation of resources. While balanced capacity and output can be realized only in the case of certain costs, subsidies, product differentiation levels, and demand price elasticity. To some extent, therefore, excess capacity is universal.

\section{Conclusions}

As studied above, this paper draws the following conclusions: (1) The ownership of capacity decision authority for higher education will affect the formation of excess capacity. Excess capacity will appear when the university owns the capacity decision authority, and there is a negative correlation between product differentiation and excess capacity. However, if the capacity decision authority is turned into the hands of the government, it is likely for excess capacity, insufficient capacity, and balanced capacity and output to emerge. There is a positive correlation between product differentiation and excess capacity. (2) The higher the subsidy of one party or the lower the cost, the higher the excess capacity level, and the lower the excess capacity level 
of the other party. (3) When universities have the capacity decision power, $\eta$ and excess capacity takes on an inverted U type relationship. When the government controls over capacity decision power, there is a negative correlation between the two in most cases.

The inspirations of these conclusions in the development of policies on the structural excess capacity of higher education in China lie in: (1) The universities should objectively treat excess capacity in the source market of students. Sometimes the excess capacity is unavoidable, and there is no need to do a gamble in order to de-capacity. As long as it helps increase social welfare, the indispensable excess capacity is reasonable. (2) The universities should accurately catch the demand in the source market of students, dynamically grasp the demand price elasticity, flexibly adjust the enrollment to appropriate scale, and facilitate the optimal allocation of higher education resources. (3) The universities should harden the state constraints on the budget of universities, allocate government subsidy funds reasonably, achieve the fairness of interregional investments, curb the vicious soft budget constraints, and implement a strict dynamic assessment mechanism. (4) The universities should intensify the management of student admissions, disciplines, and majors, and encourage the characteristic development of universities, suppress homogenous vicious competition, enhance the linkage between higher education and social demands, and strengthen the universities' initiative to operate, motivate universities to improve the efficiency of training for students and reduce the costs.

\section{References}

Barcena-Ruiz, J. C., \& Garzón, M. B. (2007). Capacity choice in a mixed duopoly under price competition. Economics Bulletin, 12(26), 1-7.

Dixit, A. K., \& Stiglitz, J. E. (1977). Monopolistic competition and optimum product diversity. American Economic Review, 67(3), 297-308, https://www.jstor.org/stable/1831401.

Lin, Y., Wu, H. \& Xing, Y. (2010). "Wave Phenomena" and formation of excessive capacity. Economic Research Journal, 10, 4-19.

Lu, Y., \& Poddar, S. (2005). Mixed oligopoly and the choice of capacity. Research in Economics, 59(4), 365374, https://dx.doi.org/doi:10.1016/j.rie.2005.09.004.

Lu, Y. \& Poddar S. (2010). The choice of capacity in mixed duopoly under demand uncertainty. Manchester School, 74(3), 266-272. https://dx.doi.org/10.1111/j.1467-9957.2006.00492.x.

Nakamura, Y. (2014). Capacity choice in a duopoly with a consumer-friendly firm and an absolute profitmaximizing firm. International Review of Economics \& Finance, 34, 105-117. https://dx.doi.org/10.1016/j.iref.2014.07.004

Ogawa, H. (2006). Capacity choice in the mixed duopoly with product differentiation. Economics Bulletin, 12(8), 1-6.

Ogawa, H. \& Nishimori, A. (2004). Do firms always choose excess capacity? Economics Bulletin, 12(2), 1-7.

Tomaru, Y., Nakamura, Y., \& Saito, M. (2011). Strategic managerial delegation in a mixed duopoly with capacity choice: partial delegation or full delegation. Manchester School, 79(4), 811-838.

Vives, X. (2006). Commitment, flexibility and market outcomes. International Journal of Industrial Organization, 4(2), 217-229. https://dx.doi.org/10.1016/0167-7187(86)90032-9. 
Wen, M., \& Sasaki, D. (2001). Would excess capacity in public firms be socially optimal?. Economic Record, 77(238), 283-290. https://dx.doi.org/10.1111/1475-4932.t01-1-00023.

Xu Z., \& Zhou N. (2015). The endogenous change of market structure and the harnessing of excessive production capacity. Economic Research Journal, (2), 75-87.

He, J., \& He, L. (2016). Do the supportive policies for photovoltaic industry work? - Evidence from Chinese stock market. Modern Economic Science, (1), 58-67,126.

Yuan, L. (2010). The allocation of China's higher education resources from the perspective of "excess capacity", Contemporary Education Sciences, (21), 90-91.

Yu, D., \& Lv, Y. (2015). Government improper intervention and overcapacity of strategic emerging industries-A case study of Chinese photovoltaic industry. China Industrial Economics, (10), 53-68. http://dx.doi.org/10.19581/j.cnki.ciejournal.2015.10.005

Zhang, H. (2012). The era of double overcapacity in higher education is coming?. Education Science, 28(2), 70-76.

Zhou, R., \& Liao, H. (2014). Ownership heterogeneity, incentives of local officials and excess capacity of China: analysis based on the dynamic stochastic general equilibrium. Industrial Economics Research, (3), 32-41. http://dx.doi.org/10.13269/j.cnki.ier.2014.03.004. 